\title{
General teams in psychiatry
}

\section{Christopher F. Fear}

\begin{abstract}
SUMMARY
The past three decades in the UK have seen a prolonged experiment in community mental healthcare that has attempted to address the problem of the disgorgement of institutional psychiatry into a poorly prepared community service. The effectiveness of new 'functionalised' service models is considered, together with a reminder of the fundamental components of community mental healthcare and a statement of the principles that should inform future service models.

\section{DECLARATION OF INTEREST}

None
\end{abstract}

\section{The past}

Advances in care for people with mental illnesses have been driven largely by fashion rather than in response to clinical evidence. The international move from institution to community progressed slowly in the UK, seeing dramatic acceleration under the reduced public financing of the Thatcher government (Thornicroft 1989): the community mental health team (CMHT) was born. CMHTs were poorly resourced and had to build experience of community care 'on the job'. This, inevitably, gave rise to errors in care, mostly minor, some resulting in high-profile homicides that were exploited by the tabloid press. The popular backlash gave rise to public inquiries that were perceived to blame 'errors' on psychiatrists and CMHTs, rather than on the poorly conceived system of care (Deahl 1997). There followed supervised discharge, 'dangerous severe personality disorder' and, in 2007, revisions to the Mental Health Act 1983 that set lower thresholds for detention and introduced community treatment orders to ensure compliance.

Meanwhile, some areas were trialling novel models of care in which different teams were developed that focused on particular patient characteristics or aspects of patient care: socalled 'functional teams'. Crisis response and home treatment (CRHT), assertive outreach (AO) and early intervention in psychosis (EIP) teams promised defined approaches, measurable outcomes and new investment to answer public and professional criticism. Available evidence became the National Service Framework for Mental Health (NSF-MH). These new service models were driven by charismatic leaders whose disciples conferred specialness on their patients. Excellent research funding, the pick of staff and facilities, shared identity, fidelity to model, rigid inclusion/ exclusion criteria, and patients hand-picked so as to benefit provided the evidence base that drove national expansion of the model, overcoming local knowledge and objective evaluations of the 'evidence' with promises of additional funding. Early adopters benefited from new funding: later adopters needed 'matched funding' to release central monies.

Early benefits appeared to support the approaches. Sadly, once novelty settled to routine, it became more difficult to attract staff and the services suffered as a result. These developments destabilised CMHTs, some of which were still working alongside their 'functional' partners. The requirement for matched funding led to the denuding of local services, which lost their best staff and retained a caseload of patients who did not fit 'fidelity' criteria for newer teams. An attempt was made to define the CMHT along the same lines as functional teams, but without the impetus to develop or an evidence base (Department of Health 2002). As novel services settled into business as usual, the initial energy reduced and many services fragmented into quarrels over referrals, with patients falling through gaps in the system. Moreover, the models of service around the UK, far from being uniform and evidence-based, were often markedly different from provider to provider.

\section{The present}

Fifteen years on from the NSF-MH, the evidence base for the teams that it introduced is poor: research is expensive, complex and of little importance in circumstances where 'functionalised' services are a fact of life. Functional teams may have been made to work well in some areas, but recent reviews have considered the evidence base and found little to show their benefits. Although Murphy et al (2014) considered CRHT to be 'a viable and acceptable way of treating people with serious mental illnesses', he concluded, for teams prescribed nationally for at least a decade, that 'if this approach is to be widely implemented it would seem that more evaluative studies are still needed'. Assertive outreach has been likened to 'dogma'
Christopher Fear is a consultant psychiatrist and Associate Medical Director of 2gether NHS Foundation Trust, Herefordshire. Correspondence Dr Christopher Fear, 2gether NHS Foundation Trust, Albion Chambers, 111 Eastgate Street, Gloucester GL1 1PY, UK. Email: chris.fear@glos.nhs.uk 
rather than a testable clinical approach. Patients of assertive outreach teams are happier with services, but there is no difference in hospital admission rates, or clinical or social functioning (Killaspy 2006). For early intervention services, Marshall \& Rathbone (2011) concluded that there is insufficient evidence to support an early intervention approach over standard community care.

An unpublished survey of members by the Faculty of General Adult Psychiatry of the Royal College of Psychiatrists in 2012 found that a significant proportion of mental health providers are reorganising services to make crisis response and home treatment, assertive outreach and early intervention in psychosis specialist components of CMHTs; there has also been a focus on developing services to support management of patients with chronic mental health problems in primary care. Indeed, it could be hypothesised that the advent of functionalised services would have been unnecessary if CMHTs had been properly conceived in the first place. This return to CMHTs with enhanced expectations of integral specialist functions could represent a maturation of community care to provide a wider range of essential functions in a coordinated fashion.

All community services use identical physical and psychosocial interventions. Medications are no different; cognitive, psychodynamic and family therapy techniques are the same; there is the same access to third-sector, community and employment resources. The only thing that functional teams do differently is to work with smaller, more selected case-loads that are simply subsets of those in generalist teams. Artificial boundaries in functionalised services can risk patients falling through gaps in provision or losing the benefits of continuity and consistent therapeutic relationships with named clinicians. Nevertheless, there is no reason why this model of service cannot work, given the will of the clinicians involved to overcome boundaries and parochialism in delivering it.

\section{The future}

The multidisciplinary model of general community mental health teams was developed for a reason. It brings the eclectic skills of diverse professional disciplines together in the expectation of delivering optimal outcomes (Burns 2004). The problem of these teams is neglecting to collect outcome data to demonstrate their effectiveness. In their failure to emphasise the need for standardised outcome measures, as well as their reluctance to grasp and understand a changing health environment, it could be argued that many psychiatrists have let down the teams and services they purport to lead. Indeed, there is an urgent need for more research using case-mix adjusted outcomes to compare the benefits of services using functional teams, those restricted to CMHTs and those where a hybrid model is in place.

In its guide to community mental health, the Joint Commissioning Panel for Mental Health (for which I was an advisory expert) concluded that no single community care approach will be 'ideal' for all areas (JCPMH 2013). Different local interpretations of service design over the past 30 years, compounded by periodic directives from local and national commissioning priorities, mean that the best that can be offered in the ongoing scramble to cut and reorganise services is the use of a set of key principles in providing goodquality community care. The commitment of professionals and commissioners to deliver a highquality service is more important than 'fidelity' to any purist model of delivery. Community care must be multidisciplinary, driven by commitment to patient-focused, quality care, delivered as close to primary care as possible, and without discrimination on grounds of age or intellect. Clear, unequivocal care pathways guarantee patient experience, ensuring that artificial team boundaries do not prevail. Outcome measures are an essential component to which psychiatrists, as clinical leaders, must strive if quality is to be assured (Kosky 2014). Personalisation, partnerships, collaborative care, social inclusion, and promotion of mental health and well-being are core targets for community services. The ability to make care work for patients will remain the best indication of a committed, skilled and dedicated body of local mental health professionals.

\section{References}

Burns T (2004) Community mental health teams. Psychiatry, 3: 11-4.

Deahl M, Turner T (1997) General psychiatry in no-man's land. British Journal of Psychiatry, 171: 6-8.

Department of Health (2002) Mental Health Policy Implementation Guide: Community Mental Health Teams. Department of Health.

Joint Commissioning Panel for Mental Health (2013) Guidance for Commissioners of Community Specialist Mental Health Services. JCPMH.

Killaspy H, Bebbington P, Blizzard R (2006) REACT: a randomized evaluation of assertive community treatment in north London. BMJ, 332: 815-9.

Kosky N, Mynors-Wallis L, Fear C, et al (2014) Service Models in Adult Psychiatry (College Report CR188). Royal College of Psychiatrists.

Marshall M, Rathbone J (2011) Early intervention for psychosis. Cochrane Database of Systematic Reviews, 6: CD004718.

Murphy S, Irving CB, Adams CE (2014) Crisis intervention for people with severe mental illnesses. Cochrane Database of Systematic Reviews, 10: CD001087.

Thornicroft G, Bebbington P (1989) Deinstitutionalisation - from hospital closure to service development. British Journal of Psychiatry, 155: 739-53. 